\title{
To Study the Effectiveness of Cyriax Manual Therapy Vs. Muscle Energy Technique in Subjects with Tennis Elbow on Pain, Grip Strength and Functional Disability
}

\author{
Avnee Sarin*, Jetly S and Michael
}

Department of Orthopedics, D.A.V. Institute of Physiotherapy and Rehabilitation, Jalandhar, India

\begin{abstract}
Introduction: Tennis elbow is a syndrome characterized by an insidious onset of elbow pain brought on by wrist extension with pronation or supination and aggravated by gripping. Tennis elbow affects $1 \%-3 \%$ of the population.

Objective: To compare the effectiveness of Cyriax manual therapy and Muscle Energy Technique in pain, grip strength and functional disability in subjects with tennis elbow.

Methodology: A minimum of 45 subjects were taken for the study. Convenient sampling technique was done, with three equal groups of 15 subjects i.e. Group A (control) received ultra sound, static stretching, eccentric exercises. Group B received ultrasound, Cyriax manual therapy, static stretching and eccentric exercises. Group $C$ received ultrasound, Muscle Energy Technique, static stretching, eccentric exercises. Treatment was given for 8 sessions within two weeks.
\end{abstract}

Results: The result showed significant improvement in Grip Strength, VAS and PRTEE within three groups. Intergroup analysis showed that there was non-significant difference between the effectiveness of Cyriax Manual Therapy and Muscle Energy Technique in patients with tennis elbow.

Conclusion: Cyriax Manual Therapy and Muscle Energy Technique are equally effective in decreasing pain, functional disability and increasing grip strength in subjects with tennis elbow.

Keywords: Tennis elbow; Cyriax manual therapy; Muscle energy technique; Patient rated tennis elbow evaluation questionnaire; Visual analogue scale; Hand dynamometer

\section{Introduction}

The syndrome of persistent disabling pain in the elbow, predominantly in the radio humeral joint, is called as tennis elbow, lateral epicondylitis, or lateral epicondylalgia [1]. Tennis elbow is a syndrome characterized by elbow pain brought on by wrist extension with pronation or supination and aggravated by gripping [2]. The prevalence of lateral epicondylitis is estimated to be $1.3 \%$ to $2.8 \%$ in the general population and up to $15 \%$ in the high-risk occupation that includes butchers, manual laborers, and employees in the fish processing industry [3]. Chief complaints in tennis elbow are decreased grip strength, decreased functional activities, and increased pain, which may have significant impact on activities of daily living [4]. It is caused by overuse or repetitive strain caused by repeated extension (bending back) of the wrist against resistance like activities such as tennis, badminton or squash but is also common after periods of excessive wrist use in day-to-day life repetitive activities such as using a screw driver, painting or typing [5]. Muscle energy techniques (METs) have been used increasingly to treat some musculoskeletal disorders, with claimed effectiveness for a variety of purposes including lengthening a shortened or muscle contracture, and increasing the range of motion of a restricted joint [6]. Cyriax and Cyriax claimed substantial success in treating tennis elbow using deep transverse friction (DTF) in combination with Mill's manipulation, which is performed immediately after DTF. For it to be considered a Cyriax intervention, the two components must be used together in the order mentioned [1]. However no study exists which compares the effects of Cyriax manual therapy and Muscle Energy Technique in decreasing level of pain and disability in patients suffering from Tennis Elbow.

\section{Purpose of Study}

The purpose of this study is to compare the effects of Cyriax manual therapy versus MET in subjects with tennis elbow on pain, grip strength and functional disability.

\section{Methodology}

The study is Experimental design comparative in nature. Conducted and Study was done in DAV Institute of Physiotherapy and Rehabilitation, Jalandhar and affiliated hospitals over a period of one and half year. A total of 45 subjects participated in the study with 15 subjects allocated in each group. Convenient sampling was done where first patient coming to opd was allocated to group A, $2^{\text {nd }}$ to group B, $3^{\text {rd }}$ to group $\mathrm{C}$ and so on.

1. Inclusion criteria: Age between 20 and 50 years, Both Males and Females patients with pain on lateral side of forearm with gripping and local tenderness for at least 6 weeks with unilateral involvement near extensor origin.

2. Special tests: Any of the following tests positive: Mill's test, Maudsley's test, Cozens test.

*Corresponding author: Avnee Sarin, Department of Orthopedics, D.A.V. Institute of Physiotherapy and Rehabilitation, Jalandhar, India, Tel: +918054987644; E-mail: sarinavni@gmail.com

Received: June 25, 2018; Accepted: July 18, 2018; Published: July 23, 2018

Citation: Sarin A, Jetly S Michael (2018) To Study the Effectiveness of Cyriax Manual Therapy Vs. Muscle Energy Technique in Subjects with Tennis Elbow on Pain, Grip Strength and Functional Disability. Physiother Rehabil 3: 159. doi: 10.4172/2573-0312.1000159

Copyright: @2018 Sarin A, et al. This is an open-access article distributed under the terms of the Creative Commons Attribution License, which permits unrestricted use, distribution, and reproduction in any medium, provided the original author and source are credited. 
Citation: Sarin A, Jetly S Michael (2018) To Study the Effectiveness of Cyriax Manual Therapy Vs. Muscle Energy Technique in Subjects with Tennis Elbow on Pain, Grip Strength and Functional Disability. Physiother Rehabil 3: 159. doi: 10.4172/2573-0312.1000159

Page 2 of 4

3. Exclusion criteria: Any recent history of trauma, arthritis of elbow joint, osteoporosis, hyper mobile joints, cervical radiculopathy, pregnancy, radio humeral bursitis, malignancy ,peripheral nerve entrapment (radial tunnel syndrome), corticosteroid injection to the elbow within last 3-6 months, absence of clinical signs of tennis elbow, elbow deformities and non cooperative subjects.

\section{Method of Collection of Data}

All the subjects were allocated into three equal groups of minimum 15 subjects each that is Control Group-Group A and experimental GroupsGroup B and Group C. A written informed consent was obtained from all the subjects. Subjects who met the inclusion criteria were taken for study. Required assessment of every subject was done. Total of 8 treatment sessions were given to each group within 2 weeks. VAS, grip strength using hand dynamometer and PRTEE was collected on $1^{\text {st }}$ (pre-treatment) before the treatment session, $4^{\text {th }}$ (post-treatment) and $8^{\text {th }}$ (post-treatment) treatment session (Figures 1 and 2).

1. Group A: Received ultrasound, static stretching and eccentric exercise.

2. Group B: Cyriax Manual Therapy+Group A.

3. Group C: Muscle energy technique+Group A.

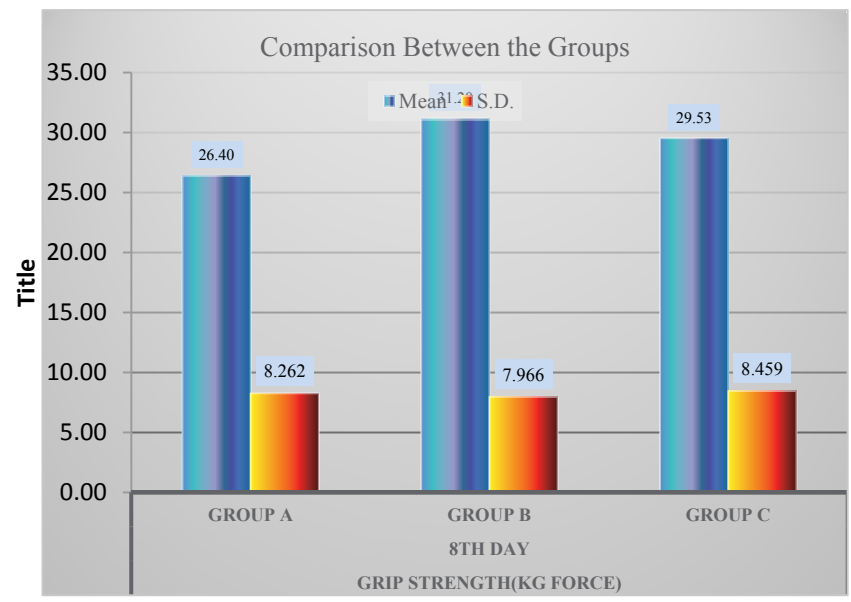

Figure 1: Comparison between groups (A, B and C) for grip strength day 8 .

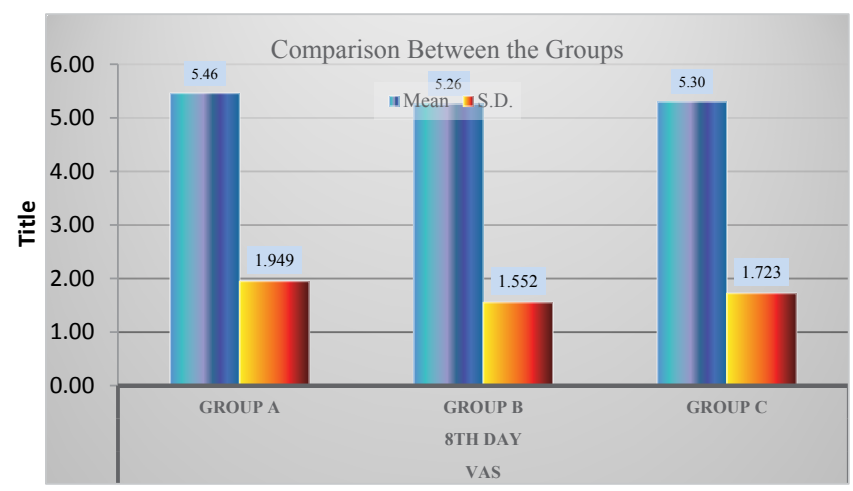

Figure 2: Comparison between groups (A, B and C) for VAS on Day 8.

\section{Interventions}

\section{Ultrasound therapy}

The patient was given with the output of $1 \mathrm{~W} / \mathrm{cm}^{2}$ for 5 minutes using a pulsed mode 1: 4 ratio with frequency of $1 \mathrm{MHz}$ [7].

\section{Static stretching}

Static Stretching for tennis elbow was applied slowly with the elbow in extension forearm in pronation, wrist in flexion and with ulnar deviation according to the patient's tolerance. This position was held for 30-45 seconds, three times before and three times after the eccentric exercises during each treatment session with a 30 seconds rest interval between each procedure [1].

\section{Eccentric exercises}

Eccentric strengthening exercise was performed by patient making a fist, with the elbow extension, forearm pronation and $40^{\circ}$ wrist extension. From here the patient then slowly pushed the wrist into flexion using the contra lateral hand to return the wrist to extension. Three sets of ten repetitions were performed with one minute rest interval between each set [8].

\section{Cyriax manual therapy}

Includes deep transverse friction massage and Mills maneuver for giving massage the patient received strong, deep friction for 15 minutes to engender hyperemia. Counter-pressure was afforded by the fingers on the medial side of the joint while the thumb crosses to and fro over the tendon [9].

\section{Mills maneuver}

It was applied immediately following the preliminary massage while hyperemia was at its height. The therapist then took up position behind the seated patient who lifted the arm to a right angle, internally rotated the shoulder and pronated the forearm. The therapist then clamped the patient's wrist into full flexion and rests the other hand lightly on the patients flexed elbow. The elbow was then snapped smartly into full extension [7].

\section{Muscle energy technique}

The therapist flexed the patients elbow to 90 degrees while monitoring the posterior head using the index finger. The forearm was supported by the stabilizing hand, while the mobilizing hand held the wrist firm. The patients forearm was rotated into the supination barrier. Then the patients gently pronated against resistance for 3 to 5 seconds. The procedure will be repeated 5 times during a single treatment session [8].

\section{Data Analysis}

Data was tabulated on master chart. Data analysis was performed using SPSS software version 20.0 (Tables 1,2 and 3).

\section{Results}

\section{Within group analysis}

Group A and B shows statistically significant improvement in grip strength measurement, pain and functional disability but in grip strength measurement and PRTEE on $4^{\text {th }}$ and $8^{\text {th }}$ day shows non-significant difference in both groups. Within group analysis of Group C shows statistically significant improvement in grip strength measurement, pain and functional disability with significant improvement with every subsequent reading (Figure 3 ). 
Citation: Sarin A, Jetly S Michael (2018) To Study the Effectiveness of Cyriax Manual Therapy Vs. Muscle Energy Technique in Subjects with Tennis Elbow on Pain, Grip Strength and Functional Disability. Physiother Rehabil 3: 159. doi: 10.4172/2573-0312.1000159

Page 3 of 4

\begin{tabular}{|c|c|c|}
\hline Groups & Day 4 (Mean \pm SD) & P-Value \\
\hline Group A vs & $26.40 \pm 8.2$ & \multirow{2}{*}{ NS $(>0.05)$} \\
\hline Group B & $31.20 \pm 7.9$ & \\
\hline Group B vs & $31.20 \pm 7.9$ & \multirow{2}{*}{ NS $(>0.05)$} \\
\hline Group C & $29.53 \pm 8.4$ & \\
\hline Group A vs & $26.40 \pm 8.2$ & \multirow{2}{*}{ NS $(>0.05)$} \\
\hline Group C & $29.53 \pm 8.4$ & \\
\hline
\end{tabular}

Table 1: Post hoc comparison between groups (A, B and C) for grip strength for day 8 .

\begin{tabular}{|c|c|c|}
\hline Groups & Day 8 (Mean \pm SD) & P-Value \\
\hline Group A vs & $5.46 \pm 1.94$ & \multirow{2}{*}{ NS $(>0.05)$} \\
\hline Group B & $5.26 \pm 1.55$ & \multirow{2}{*}{ NS $(>0.05)$} \\
\hline Group B vs & $5.26 \pm 1.55$ & \\
\hline Group C & $5.30 \pm 1.72$ & \multirow{2}{*}{ NS $(>0.05)$} \\
\hline Group A vs & $5.46 \pm 1.94$ & \\
\hline Group C & $5.30 \pm 1.72$ & \\
\hline
\end{tabular}

Table 2: Post hoc comparisons between Groups (A, B, and C) for VAS on Day 8.

\begin{tabular}{|c|c|c|}
\hline Groups & Day 4 (Mean \pm SD) & P-Value \\
\hline Group A vs & $54.13 \pm 18.84$ & \multirow{2}{*}{ NS $(>0.05)$} \\
\hline Group B & $50.40 \pm 15.31$ & \multirow{2}{*}{ NS $(>0.05)$} \\
\hline Group B vs & $50.40 \pm 15.31$ & \\
\hline Group C & $51.73 \pm 17.54$ & \multirow{2}{*}{ NS $(>0.05)$} \\
\hline Group A vs & $54.13 \pm 18.84$ & \\
\hline Group C & $51.73 \pm 17.54$ & \\
\hline
\end{tabular}

Table 3: Post hoc comparison between Groups (A, B and C) for PRTEE on Day 8.

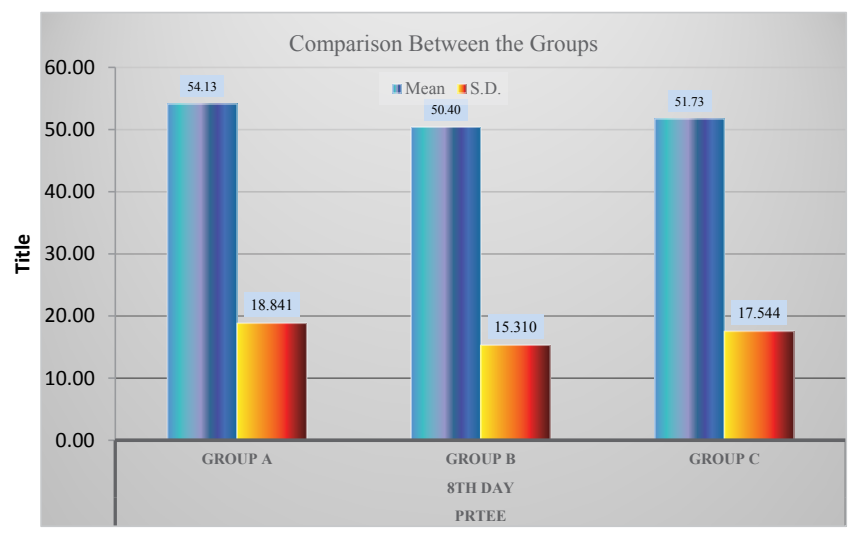

Figure 3: Comparison between groups (A, B and C) for PRTEE on Day 8.

\section{Inter-group analysis}

In inter group analysis between Groups A, B and C shows that there is statistically non-significant difference between the three groups.

\section{Discussion}

Cyriax have been effective in tennis elbow along with DTF in combination with Mill's manipulation, which is performed immediately after DTF [9]. Pain relief during and after DTF may be due to modulation of the nociceptive impulses at the level of the spinal cord: via "gate control theory" by which reduction in pain may be achieved is through diffuse noxious inhibitory controls, a pain suppression mechanism that releases endogenous opiates. In addition, the application of DTF can produce therapeutic movement by breaking down the strong cross links or adhesions that have been

formed. DTF produces vasodilatation and increased blood flow to the area. This may facilitate the removal of chemical irritants and increase the transportation of endogenous opiates, resulting in a decrease in pain [7]. In mills the intention is to shift the annular ligament which is out of place and greatest possible stretch is applied to the extensor carpi radialis muscles with a sharp jerk which tends to open up the tear in the tendon and abolish tension on the tender scar [10]. This allows the self-perpetuating post traumatic inflammation to subside and healing with permanent lengthening. Hence forth the intact part of the tendon takes all the strain, thus affording protection against the recurrences that are sometimes a problem when steroids are used [11]. This could be the reason for the improvement showed by the subjects in the present study. The present study showed MET being effective in tennis elbow which can be supported by Chaitow, which states MET is an active muscular relaxation method, normal blood circulation is restored which wipes out nociceptive stimulants from the site of pain which relieves pain [6]. As most epicondylitis is related to restriction of the radial head at the radio-humeral and proximal radioulnar joint. Myofascial restrictions are typically over a diffused area and usually respond well to myofascial release and/or muscle energy technique [12]. It is proposed that MET can release articular restrictions, lengthen muscle fibers, and increase the range of motion through a combination of creep and plastic change in the connective tissue. MET is a noninvasive, painless, safe, and easy treatment option without adverse events [12]. Stasinopoulos et al. [1] suggested that for tendons to be flexible along with strong strengthening and stretching both should be components of exercise programme. Eccentric training results in tendon strengthening by stimulating mechano-receptors in tenocytes to produce collagen, which is probably the key cellular mechanism that determines recovery from tendon injuries [8]. Further study can be performed with large sample size and asses the long term effects can be seen by prolonged follow up. Moreover future studies can done specifically on players and even various effect of techniques on various age groups can be assessed.

\section{Conclusion}

The study concludes that there is statistically non-significant difference between the two techniques, thus supporting the null hypothesis. The study can be performed with a large sample size. The study can be done in athletes only. Long term effects can be seen by prolonged follow up.

\section{References}

1. Stasinopoulos D, Stasinopoulou K, Johnson MI (2005) An exercise programme for the management of lateral elbow tendinopathy. Brit J Sports Med 39

2. Kushner S, Reid DC (1986) Manipulation in the treatment of tennis elbow. J Orthopaed Sports Phys Ther 7: 264-272.

3. Khandaker MN, Islam S, Emran MA, Islam J, Ahmed SM, et al. (2014) The effect of stretching exercise in the management of lateral epicondylitis. Banglad Med J 43: 61-66.

4. Viswas R, Ramachandran R, Anantkumar PK (2012) Comparison of effectiveness of supervised exercise program and cyriax physiotherapy in patients with tennis elbow (lateral epicondylitis): A randomized clinical trial Scient World J 2012: 1-8

5. Waseem M, Nuhmani S, Ram CS, Sachin Y (2012) Lateral epicondylitis: A review of the literature. J Back Musculoskel Rehabil 25: 131-142.

6. Küçükşen S, Yilmaz H, Sallı A, Uğurlu H (2013) Muscle energy technique versus corticosteroid injection for management of chronic lateral epicondylitis: randomized controlled trial with 1-year follow-up. Arch Phys Med Rehabil 94: 2068-2074.

7. Hariharasudhan R, Balamurugan J (2015) Effectiveness of muscle energy technique and Mulligan's movement with mobilization in the management of lateral epicondylalgia. Arch Med Health Sci 3: 198-202. 
Citation: Sarin A, Jetly S Michael (2018) To Study the Effectiveness of Cyriax Manual Therapy Vs. Muscle Energy Technique in Subjects with Tennis Elbow on Pain, Grip Strength and Functional Disability. Physiother Rehabil 3: 159. doi: 10.4172/2573-0312.1000159

8. Kerageanes SJ (2005) Principles of Manual Sports Medicine. (2ndedn), Lippincott Williams and Wilkins. Philadelphia, pp: 221-222.

9. Cyriax HJ, Cyriax JP (1983) Cyriax's illustrated manual of orthopaedic medicine. Oxford: Butterworth-Heinemann, pp: 59.

10. Stasinopoulos D, Johnson MI (2004) Cyriax physiotherapy for tennis elbow/ lateral epicondylitis. Brit J Sports Med 38: 675-677.
11. Nagrale AV, Herd CR, Ganvir S, Ramteke G (2009) Cyriax physiotherapy versus phonophoresis with supervised exercise in subjects with lateral epicondylalgia: a randomized clinical trial. J Man Manipul Ther 17: 171-178.

12. Bag T, Patra P, and Kumar N (2015) Comparison of effects of mill's maneuver and stoddard's maneuver for the treatment of chronic lateral epicondylitis. Ind J Phys Ther 3. 